\title{
Desenvolvimento do Turismo e a Interface com a Instância De Governança estadual: Um estudo no Rio Grande do Norte/Brasil
}

\section{Ana Catarina Alves Coutinho* Francisco Fransualdo Azevedo**}

Universidade Federal do Rio Grande do Norte (Brasil)

\begin{abstract}
Resumo: Na nova ordem econômica internacional que tornou as economias assimétricas impactando nas dinâmicas locais, ocasionando também uma interferência no processo de planejamento e gerenciamento da atividade turística. Neste sentido, este trabalho analisa como o processo de desenvolvimento da atividade turística, caracterizada pela forma de uso do território turístico por meio do seu gerenciamento, influencia na dinâmica e funcionamento de uma instância de governança em turismo. A pesquisa realizou coleta de dados do tipo documental, bibliográfica e entrevista com os membros do conselho estadual de turismo do Rio Grande do Norte (RN), cujos dados foram tratados com a técnica de análise de conteúdo, baseada no método dialético. Os principais resultados evidenciam que as características do processo de desenvolvimento da atividade turística no RN repercutem diretamente na instância de governança estadual evidenciado através da sua estrutura de funcionamento, da dinâmica, bem como das ações que são engendradas dentro do conselho.
\end{abstract}

Palavras-chave: Desenvolvimento turístico; Instância de Governança; Planejamento turístico; Rio Grande do Norte.

Tourism Development in Rio Grande do Norte and Interfaces with the State Governance Instance: A study in Rio Grande do Norte / Brazil

Abstract: In the new international economic order that made the asymmetric economies impact on the local dynamics, causing also an interference in the process of planning and management of the tourist activity. In this sense, this work analyzes how the process of tourism development, characterized by the way tourism is used the territory through its management, influences the dynamics and functioning of a governance in tourism. The research carried out data collection of the documentary, bibliographic and interview with the members of the state tourism council of Rio Grande do Norte $(\mathrm{RN})$, whose were treated with the technique of content analysis, based on the dialectical method. The main results show that the characteristics of the process of development of the tourist activity in the RN have a direct impact on the state governance body evidenced through its functioning structure, the dynamics, as well as the actions that are generated within the board.

Keywords: Tourism development; Governance Body; Tourist planning; Rio Grande do Norte.

\section{Introdução}

O turismo tem sido um dos aspectos mais marcantes da sociedade contemporânea, fixando sua importância, por meio dos inúmeros reflexos que o setor tem gerado nas localidades. No estudo do desenvolvimento do turismo, conceitos como renda, receita, fluxo, demanda e oferta são largamente difundidos e, apesar das opiniões divergentes, acabam por retratar uma parcela da importância do setor, mas não sua complexidade. A dimensão econômica do turismo está associada aos mecanismos por meio dos quais o sistema capitalista tenta superar as crises econômicas, resultando em uma (re) produção e alimentação acelerada do capital.

Universidade Federal do Rio Grande do Norte (Brasil); E-mail: coutinho.catarina1@gmail.com

Universidade Federal do Rio Grande do Norte (Brasil); E-mail: ffazevedo@gmail.com 
Assim, o mundo a partir da inserção da nova ordem econômica internacional tornou as economias assimétricas que passaram a ser fortemente afetadas por outras economias, tanto internas quanto externas, estando a todo tempo articulada. Os espaços se tornaram mais homogêneos e competitivos em uma relação de dicotomização. De um lado, exigem-se produtos e ações singulares para que possam se destacar nesse novo cenário por meio da heterogeneidade; e de outro a homogeneidade, transportando modelos de sucessos, incentivados pelas políticas federais.

O território deixa de ser do Estado e passa a ser transnacional, estabelecendo a revolução técnico-científica, visto que a ciência, a tecnologia e o conhecimento passam a ser trabalhados em conjunto, em um processo cada vez mais veloz, instantâneo, fluido, superficial e individual, impondo um novo ritmo à sociedade, no caso, as redes (Santos, 2010; Cacho \& Azevedo, 2010, Azevedo et al, 2013).

Assim, com o objetivo de analisar como ocorre o processo de desenvolvimento da atividade turística em um estado brasileiro - Rio Grande do Norte (RN), este artigo busca caracterizar como acontecem as formas de uso do território turístico por meio do gerenciamento da atividade turística e como estas ações interferem na dinâmica e funcionamento da sua instância de governança estadual.

O estudo sobre governança permite compreender fenômenos complexos como o turismo, uma vez que possibilita uma gestão compartilhada e participativa, conhecendo, de perto, a realidade dos processos de gestão do turismo. Esse é o tipo ideal de gestão que reflete no processo desenvolvimento do turismo, que, conforme sua atividade é bastante complexa.

Importa destacar, ainda, que a atividade turística necessita de planejamento e de gestão eficiente; logo, as instâncias de governança se tornam fundamentais, uma vez que, por meio da interação de diversos setores e vozes no processo de implementação, gestão e controle, é possível tomar decisões, planejando o turismo de maneira articulada. A discussão de governança em turismo ainda é incipiente com um olhar crítico e profundo que considere as relações, processos e resultados sobre seus desdobramentos, e como essas relações podem influenciar as decisões. Desse modo, acredita-se que este trabalho possa contribuir para entender a dinâmica, processo e funcionamento do desenvolvimento turístico no $\mathrm{RN}$ e os reflexos no Conselho Estadual de Turismo (Conetur), obtendo diferentes atores na sua constituição para o processo de planejamento e gestão da atividade turística no estado do RN.

\section{O papel do Estado no direcionamento da atividade turística: o uso do território turístico}

Ao longo dos séculos, mudanças sociais fizeram o Estado assumir diversas posturas, no intuito de responder a um ambiente que têm diversos interesses e poderes de pressões diferenciados. Assim, surge o Estado moderno, o Estado absolutista, o Estado socialista, o Estado capitalista e o Estado liberal, como exemplos de regimes adotados para garantir um maior controle e legitimidade, tanto pelos meios de produção, quanto pelo meio social. O Estado, desta forma, assume diversos papéis em cenários diferenciados, considerando as diversas pressões que sofre.

Dias \& Matos (2012) defendem que o papel do Estado deve ser de quatro tipos: regulador, facilitador, aliado e apoiador nas decisões públicas e afirmam que "os quatro papéis não necessariamente devem ser desempenhados separadamente, nem mesmo excluem-se os mecanismos de um em relação ao outro" (p. 193), deve ser pensado como uma mescla de fatores para atender os diversos interesses existentes no jogo político contemporâneo.

Por sua vez, Velasco González (2013; 2016) e Tretin (2016), em uma visão mais objetiva, ressaltam a necessidade de um papel de coordenador frente aos objetivos conflitantes que assume no mundo contemporâneo. A OCDE (2013) também reforça a necessidade de uma postura coordenadora como forma de melhorar os resultados das ações públicas e gere resultados positivos na constituição da governança turística.

No entanto, é importante considerar, que nos últimos anos, foi promulgada uma nova forma de se fazer política no mundo e consequentemente no Brasil, que influencia na forma do desenvolvimento das localidades que passou a ser baseada em ideais descentralizadores, mas que não foi acompanhada de capacidade institucional de cada governo municipal. Guimarães (2002) destaca que os resultados da descentralização são condicionados pela conjuntura onde está inserida e pelas visões de mundo contempladas em suas propostas. Corroborando com este pensamento, Arretche (1998) em estudo realizado, afirma que a descentralização brasileira tem como foco a disputa de elites locais, emergindo uma descentralização com diversos governos centralizados.

Entende-se, desta forma, que Estado é o elemento condutor das ações e iniciativas do turismo brasileiro, podendo influenciar de forma direta nas decisões, por meio de políticas públicas, ou de forma 
indireta, em ações transversais, ou ainda, por meio de organizações no novo contexto social (Dias \& Matos, 2012; Velasco Gonzalez, 2013). Com isso, a atuação do Estado e o direcionamento das políticas públicas de turismo contemporâneas são movidos por uma questão complexa, interdependente e dinâmica, correlacionando com diversos setores para o seu êxito, principalmente em um contexto onde discute-se a participação social como um tema recorrente no âmbito das políticas públicas, relacionando à possibilidade de consolidação do senso de pertencimento e responsabilidade coletiva (Velasco Gonzalez, 2016; Tretin, 2016; Baum, 1994; Emmedoerfer et al, 2016; Wan \& Bramwell, 2015).

Entretanto, apesar de todas as mudanças institucionais, vivenciadas nos últimos anos, a partir da criação de instrumentos que passou a incluir a sociedade no processo de planejamento público considerando o processo de descentralização, observa-se fragilidades neste contexto que é marcado por contradições que vivencia uma democracia ainda recente e frágil, impedindo o debate aberto com controle e decisões participativas. Esse processo permitiu a formulação de três formas distintas de participação, teorizada por Alió (2005), demonstrada no quadro 01. Para a autora, este é o cenário do processo de avanço dos sistemas participativos contemporâneos.

De acordo com a Alió (2005), o primeiro modelo reúne uma série de mecanismos para que a participação e colaboração de todos os envolvidos se efetivem. Esse é um modelo ideal de participação, requerendo um alto nível de percepção por parte da gestão e envolvimento por parte da comunidade. Exemplos como esses são difíceis de acontecer. O segundo modelo pode ser classificado como misto ou de transição, em que aparecem formas pontuais para a inclusão dos cidadãos na política. Este é o caso de algumas consultas populares. O terceiro e último modelo de participação é limitada, e, embora seja bastante difundido, fica subordinado às formas e decisões da liderança administrativa, legitimada por meio do sistema de participação representativa. Essa é uma das formas mais usuais da atualidade.

\section{Quadro 1: Modelos de participação social nas decisões públicas}

Modelo participativo de decisão: Municípios com regulamentos ou organismos de participação que possibilitem o acompanhamento e controle da gestão local, bem como a participação e colaboração dos cidadãos na definição das políticas locais que afetam todos os cidadãos.

Modelo participativo de suporte: Municípios com regulamentos ou organismos de participação, informação e consulta da gestão local, onde os cidadãos têm o direito de ser informado e consultado. O modelo busca o consenso e o apoio social as políticas de gestão local tomadas anteriormente pelo município. Este modelo cria frustração, incompreensão e conflitos entre os cidadãos envolvidos no processo e a prefeitura, que visa responsabilizar os cidadãos das decisões formuladas a partir do 'conhecimento' e 'objetividade' das administrações públicas.

Modelo participativo restrito: Municípios sem a existência de qualquer instrumento, sistema ou regulamento de participação e consulta cidadã. As consultas são pontuais, geralmente restringidas a grupos sociais econômicos específicos que exercem o 'grupo de interesses' locais. Os cidadãos devem defender seus direitos por canais não definidos com claridade e geralmente arbitrários, situação que provoca divergências e confrontos entre os cidadãos e a prefeitura.

Fonte: Alió (2005). Tradução nossa.

No entanto é importante considerar a dimensão e a diversidade do território brasileiro que tornam a gestão da atividade turística um dos grandes desafios que são impulsionadas pelo processo de globalização, abertura dos mercados e internacionalização do capital que desempenham um papel determinante nas ações e estruturação do espaço. Emmedoerfer et al (2016), sinaliza que lidar com um federalismo de relações governamentais de configuração quadrigovernativa (quatro níveis: federal, estadual, regional e municipal) é um grande desafio, uma vez que remetem a problemas de coordenação e de planejamento de políticas.

O entendimento de desenvolvimento turístico nesta pesquisa está diretamente relacionado a forma como o território é ocupado, devido as questões contemporâneas que incidem sobre ele. Assim, um primeiro passo para discutir o uso do território, e nesse caso, o território ocupado pelo turismo, recorre-se, necessariamente, a sua definição, e consequentemente a sua constituição por meio de seus rebatimentos. De acordo com Santos (2002), o território é definido através de seu uso: "É o uso do território, e não o território em si mesmo, que faz dele objeto da análise social. Trata-se de uma forma impura, um híbrido, uma noção que, por isso mesmo, carece de constante revisão histórica". (Santos, 2002:7, grifo nosso). 
O território, assim, é um elemento fundante para a compreensão das relações sociais contemporâneas no desenvolvimento do turismo, principalmente considerando o Estado como norteador do direcionamento das ações de fomento ao turismo. Segundo Santos (2010), o território é um produto da sociedade definido por meio de suas relações. O seu uso pode ser definido, dentre outras possibilidades, pela implantação de infraestruturas, denominados de sistema de engenharia, mas também pelo dinamismo da economia e da sociedade. Entretanto, como se trata do uso do território pela atividade turística e não existe turismo sem deslocamento e fluxos, é evidente que haja modificações no espaço. Faz-se necessário, assim, diferenciar a infraestrutura indispensável à modernização do território daquelas criadas no intento de atrair investimentos. O primeiro uso visa à construção de relações horizontais ao passo que o segundo uso é ancorado no sistema de relações verticais.

Não é todo o território que é ocupado turisticamente. A atividade faz uso pontual e seletivo desse território, criando diversas formas, permitindo ser tanto uma prática social devido ao intercâmbio de pessoas, como também de segregação, dotando alguns espaços de infraestrutura, em detrimento de outros. Gera-se, assim, contrarracionalidades e contraposições, face aos benefícios concedidos a setores pontuais.

Corroborando o pensamento de Raffestin (1993), o território, além de ser um produto social, incute relações de poder, em um campo de forças onde se projetou um trabalho. O poder é exercido pelo povo e não pode ser possuído ou adquirido, mas simplesmente exercido. Produzindo território, se está produzindo poder em uma problemática relacional. O jogo de poderes determinará os diversos interesses na atividade turística.

Assim, o território implica uma interação econômica, social, política e cultural que resulta em jogos de troca. Isso conduz a um sistema de redes, organizadas, hierarquicamente, permitindo o controle sobre aquilo que pode ser distribuído, possuído ou disponível, isto é, uma relação de poder (Raffestin, 1993). Com isso, as ações dos diversos atores e agentes que produzem o território turístico serão medidas por essas relações de poder, onde um ou outro setor pode ser bem representado.

Conjunturas antigas, de acordo com Raffestin (1993), podem sobreviver em novos espaços, visto que são sustentadas pelas relações vividas pelas populações, pelas relações econômicas existentes, pelos costumes, etc. É o intercâmbio e relação entre essas pessoas que imprimem certo sentido à atividade. Portanto, essa arena que constitui os conselhos, produzem territórios baseados em relações sociais de poder com expectativas e objetivos divergentes uma das outras. Conciliar esses interesses faz parte do território usado e deve constituir uma ação, norteada pelo planejamento de suas políticas públicas que tem o Estado como direcionador de suas ações e que conforme preconiza a literatura, há uma defesa de uma postura coordenadora (Velasco Gonzalez, 2013; 2016; Dias \& Matos, 2012; Tretin, 2016) diante do cenário conflitante e dinâmico em que se depara, principalmente no cenário de participação social (Alió, 2005).

\section{Procedimentos metodológicos}

Em consenso com autores de estudos metodológicos (Richardson, 2008; Godoy, 1995; Gil, 1994) este artigo se caracteriza como descritivo-exploratório quanto aos seus objetivos. E em relação ao tratamento do objeto, nomeia-se pesquisa qualitativa. O método escolhido para esta pesquisa é o dialético que permite analisar o cenário utilizando a própria realidade como argumento, isto é, confrontando a teoria (o que as normas, falas e relatórios afirmam) com a sua empiria (a operacionalização, concretização).

Caracteriza-se como estudo de caso, por ter uma unidade, no caso o Conselho Estadual de Turismo (Conetur), que se analisa profundamente, buscando novas descobertas, por meio das múltiplas fontes de evidências. Por se tratar de um tema complexo, percebeu-se a chance de realizar um exame dessa natureza com o objetivo de esclarecer e contribuir para o conhecimento acerca da governança, exatamente por se constituir uma temática recente de investigação no estado, obtendo, como participantes desta pesquisa, os sujeitos que integram o Conetur. Esses sujeitos compõem representações de diversos setores: público, privado e terceiro setor, totalizando, dessa forma, 35 representantes.

Para a análise da instância de governança como um reflexo do processo de desenvolvimento local foram definidos dois tipos de documentos. O primeiro visa analisar o seu desenho institucional, por meio de sua estrutura organizativa, sua composição e os processos de funcionamento - Regimento Interno de criação do Conetur do ano de 2009. E o segundo, compreende a dinâmica de funcionamento, ou seja, as atas das reuniões ordinárias e extraordinárias, totalizando 33 atas que existiam e/ou foram disponibilizadas.

Ademais, o estudo faz uso de pesquisa bibliográfica e são realizadas entrevistas com os membros do conselho estadual com roteiros semiestruturados, que foram gravadas e transcritas com o consentimento 
e autorização dos participantes e posteriormente foi realizada a análise de conteúdo do tipo análise estruturadora do conteúdo, buscando tipos ou estruturas formais na codificação das respostas (quadro 02).

Quadro 2: Codificação para análise dos resultados

\begin{tabular}{|c|c|}
\hline Setor de representação & Código \\
\hline Setor Federal & SF \\
\hline Esfera Estadual & EE \\
\hline Esfera Regional & ER \\
\hline Esfera Municipal & EM \\
\hline Iniciativa Privada & IP \\
\hline Terceiro Setor & TS \\
\hline
\end{tabular}

Fonte: elaboração própria.

Posteriormente, com base nos conteúdos obtidos, foi realizada a triangulação dos dados (documentos, bibliografia e entrevistas), como forma de prezar pela validade dos dados, trazendo respostas mais fidedignas para a questão de investigação deste trabalho.

\section{A Gestão e o crescimento da atividade turística no Rio Grande do Norte}

O desenvolvimento turístico no Brasil, conforme destaca alguns autores (Emmedoerfe et al, 2011; Cruz, 2000; Emmedoerfer et al, 2016), tem demonstrado dois marcos no que tange a gestão pública. O primeiro de 1930 até 1990 é caracterizado pela centralização do Estado e pela verticalização da política nacional de turismo, com estruturas de forte dependência dos interesses organizacionais e também com características pessoais dos formuladores da política pública nacional, período em que emerge a criação da Empresa Brasileira de Turismo (Embratur) e o Conselho Nacional de Turismo (CNT). O segundo marco, dar-se a partir de 1990, em um processo de horizontalização por meio do Programa Nacional de Municipalização do Turismo (PNMT), e posteriormente por meio da criação do Ministério do Turismo (MTur) com ideais participativos e valorização dos lugares e territórios.

Todo este sistema nacional de turismo estava inicialmente preocupado com a criação de um sistema de engenharia voltado ao ordenamento do território turístico para captar investimento estrangeiro para a construção de grandes empreendimentos hoteleiros, visando atender à intenção de uma 'nova' elite empresarial que estava emergindo no país, criando, assim, a política de megaprojetos turísticos.

$\mathrm{O}$ foco era o litoral nordestino brasileiro e, com isso, surgem as primeiras intervenções de planejamento e gestão de turismo no RN oriundas de diretrizes nacionais - de forma específica, o Projeto Parque das Dunas/Via Costeira (PD/VC) e o Programa de Ação para o Desenvolvimento do Turismo no Nordeste (Prodetur) que provocou fortes mudanças no espaço, caracterizando um cenário de internacionalização do turismo potiguar, que inicia na década de 1990, recebendo investimentos de agentes europeus, com destaque para os portugueses, espanhóis e italianos (Fonseca \& Taveira, 2009; Maranhão \& Azevedo, 2014).

Conforme aponta Fonseca (2006), a política de megaprojetos turísticos - PD/VC é um marco para o RN, visto que possibilitou a real expansão do turismo, bem como passou a ser referenciado como a primeira política de planejamento e gestão de turismo no estado. O projeto constitui-se na construção de uma via de $8,5 \mathrm{~km}$ que une as praias de Areia Preta e Ponta Negra para a construção de equipamentos, lê-se, empreendimentos hoteleiros, a partir de facilidades de empréstimos subsidiados pelo governo para a aquisição de terrenos nas localidades.

No entanto, devido à escassa infraestrutura do litoral nordestino o projeto não obteve o sucesso desejado, iniciando, assim, o Prodetur/NE, no ano de 1992, que teve como objetivo dotar o litoral nordestino de infraestrutura básica. Corroborando tal compreensão, Cruz (2000: 31) cita que "características históricas, representando menos resistência às novidades, somadas a qualidade naturais climáticas, fizeram do Nordeste brasileiro, ou melhor, do litoral nordestino, o alvo privilegiado das mudanças engendradas na década em tela”. 
Fica evidenciado, assim, o interesse estatal em investimentos externos, na perspectiva de atrair um maior número de capital estrangeiro para o estado, dotando o espaço de sistema de engenharias para a instalação desses investimentos principalmente, hoteleiros. Impulsionados por uma lógica vertical, os espaços se tornam homogêneos e competitivos desenhando a importância que o Estado adquire no direcionamento da atividade, mediada pelo processo da globalização e dos mercados.

O processo de crescimento da atividade turística no estado é norteado pela concentração dos fluxos, dos interesses e dos investimentos na capital do estado, Natal/RN, em especial aos municípios integrantes ao Polo Costa das Dunas, que, por serem a porta de entrada de fluxos de turistas e terem recursos naturais relacionados ao segmento Sol e Praia, supervalorizado no cenário nacional e também internacional, ocupando lugar de destaque, concentrando um sistema de objetos e ações, redefinindo sua forma e conteúdo para o uso turístico (Santos, 2010).

O território de uso turístico foi considerado como aspecto político-administrativo, ancorando seus benefícios no uso corporativo do território, maximizando as ações segmentadas na medida em que negligencia a concepção do espaço banal, que conforme evidencia Santos (2010), em uma análise espacial, afirma que é de todos, de todos os homens, das instituições, das organizações, ou seja, de toda uma coletividade.

A implantação desses novos objetos, principalmente aqueles voltados ao incentivo de maior circulação de pessoas, é uma necessidade da atividade turística, que, constantemente, precisa alterar a dinâmica da localidade. Para isso, a atividade sempre se vincula a uma rede de hegemonias que prepara o uso do território para o seu estabelecimento.

Gera-se, assim, contrarracionalidades, já que não possibilita a participação de atores localizados fora desse eixo central, evidenciando o interesse estatal em ter um produto centrado e pouco diversificado. Com isso, o processo de regionalização fica concentrado nas grandes capitais e/ou zonas litorâneas, e o RN justamente por ter a capital situada em uma zona litorânea, concentra o fluxo, dirimindo os interesses e potencialidades das outras regiões, que começam a se desenvolver, tardiamente, apresentando condições distintas de desenvolvimento turístico entre as regiões.

Procedendo a análise verticalizada, é possível identificar que os agentes hegemônicos realizam as intervenções que lhe são convenientes, modificando, inclusive, esses espaços para a lógica das exigências dos visitantes, ampliando e modernizando aeroportos, melhorando as vias para os fluxos turísticos, facilitando deslocamento, marginalizando os usos e interesses dos atores/agentes endógenos que utilizam do mesmo espaço para seu convívio social (gráfico 01).

\section{Gráfico 1: Investimentos do Prodetur II no Nordeste brasileiro, por setor.}

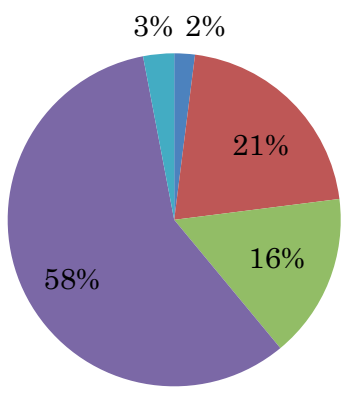

- Gestão Resíduos Sólidos

e recursos naturais

- Planejamento estratégico

- Capacitação Profissional

- Obras de Infraestrutura

- Investimento não identificado

Fonte: Banco do Nordeste, 2013.

Ademais, privilegia a formação de redes internacionais competitivas, que também justifica a lógica da verticalidade. Corroborando tal entendimento, Santos (2002) em sua análise teórica sobre território e espaço, cita que "além das redes, antes das redes, apesar das redes, depois das redes, com as redes, há o espaço banal, o espaço de todos, todo o espaço porque as redes constituem apenas uma parte do espaço e o espaço de alguns" (p. 256).

Por sua vez, a comunidade norteriograndense não consegue se articular na formação de capital social no sentido de se responsabilizar pelos processos atuais e futuros que ocorrem na localidade, 
corroborando com a reprodução de esquemas clássicos de cooptação utilizados pelos poderes hegemônicos e os contrapoderes são pífios e não adquirem notoriedade diante da magnitude das forças opressoras. A democracia ainda é entendida como direito e o único dever é o voto, sem nenhum engajamento político, nenhum interesse de se envolver nos processos de forma coletiva e cooperada. Quando ocorre, visam aos benefícios particulares por meio de troca de favores políticos, em detrimento das questões do bem comum. Valores, tais como: confiança e civilidade são limitantes nessa relação, abrindo espaço para o poder hegemônico atuar (Maranhão, 2012), baseado em critérios meramente políticos e econômicos.

Nesse contexto, Souza \& Rodrigues (2004) destacam que é raro que se pensem os ativismos sociais como fonte de soluções criativas de caminhos para solucionar os problemas. Eles não agem, apenas, como meros espectadores ou como críticos daquilo que não lhe agrada, mas também como atores propondo e buscando solução para a problemática mediante planejamentos alternativos.

Inexistem normas e procedimentos explícitos em que a sociedade possa ouvir e ser ouvida, em uma via de mão dupla, conforme evidenciado por Maranhão (2012). Tais ações são justificadas pelo binômio emprego e renda, largamente difundidos pelo poder hegemônico, como potencial mitigador das desigualdades sociais, através da baixa remuneração e condições precárias de trabalho. Todavia, sabe-se que uma visão centrada na renda não possibilita atingir o desenvolvimento autêntico e efetivo, capaz de reduzir as desigualdades existentes (Sen, 2000).

Com isso, o foco não reside, somente, na participação, mas também na observação de elementos estruturais que possibilitem a intervenção societária, considerando o poder do Estado na repressão e controle social, conforme aponta Alió (2005). Nessa conjuntura, a capacidade de governança dependerá, de um lado, da criação de canais institucionalizados, legítimos e eficientes; de mobilização e envolvimento da comunidade na elaboração e implementação de políticas, visando atender aos requisitos de uma sociedade democrática; e de outro, da capacidade de adaptação de sua estrutura governamental às exigências da economia, no sentindo de orientar-se na busca de eficiência, de racionalidade econômica e política (Azevedo \& Anastasia, 2002).

Com base no exposto, desenham-se, na figura 01, algumas características do processo de desenvolvimento turístico norte-rio-grandense que foram explicitados correlacionando com o uso do território turístico baseado em relações de poderes.

\section{Figura 01: Características do processo de desenvolvimento turístico no Rio Grande do Norte}

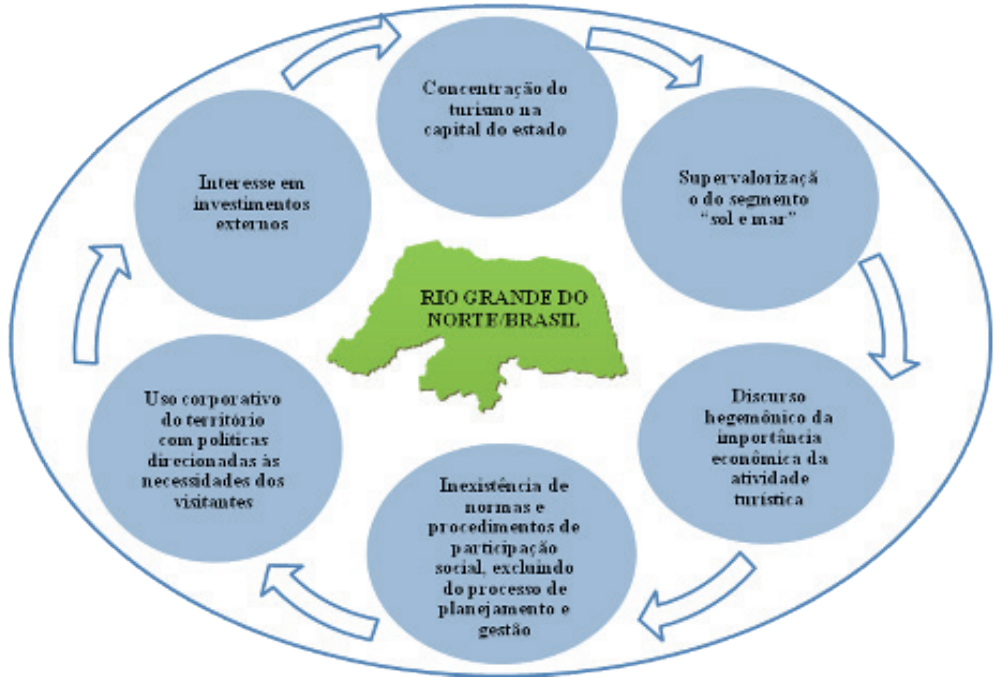

Fonte: Dados da pesquisa.

Assim, conforme vem sendo evidenciado, o desenvolvimento do turismo, no Brasil, e de forma específica no RN está pautado no viés puramente economicista e centralizado, por meio de ações pontuais no território, tornando-o segregado e altamente seletivo. Tais ações são fomentadas pelos atores hegemônicos que utilizam do binômio emprego-renda para exercer as ações de poder no território potiguar. $\mathrm{O}$ foco 
é o visitante em detrimento do uso coletivo do território, convergindo ações para atrair investimento externo, impossibilitando e excluindo a participação social no processo de planejamento e gestão da atividade turística, que não contempla procedimentos, normas e canais claros de participação.

\section{Como o desenvolvimento da atividade turística reflete na instância de governança estadual de turismo - Conetur?}

No cenário turístico, essas instâncias de governança, estimuladas pelo processo de descentralização foram instituídas por meio do Programa de Regionalização do Turismo (PRT), tendo como foco, as regiões turísticas. Assim, nesse processo de segmentação política, é necessário implementar um eficiente sistema de gestão que permita o fluxo de informações necessário, possibilitando o seu controle sobre a qualidade e quantidade.

Em face do exposto, torna-se estritamente necessária a articulação entre os diversos, evitando que as relações de poderes, produzidas, nesse território, influenciem de forma negativa nas deliberações políticas. Entretanto, é nesse jogo político que sobressaem os grupos de poderes locais. São as ideologias de um processo, que, apesar de democrático, pelo menos no sentindo do direito de voto, demonstra comportamento individualista, conduta do poder pessoal e de supervalorização de um setor em detrimento de outros.

Não obstante, a constituição de instâncias de governança é também uma das exigências do novo marco regulatório que forçou a inserção da participação social nas decisões políticas, criando, assim, quatro níveis de instâncias de governança em turismo.

No âmbito nacional, o CNT - órgão de colegiado superior de assessoramento que compõe a estrutura básica e o Núcleo Estratégico do Ministério do Turismo - tem como desígnio implementar um modelo de gestão pública descentralizada e participativa. Esse órgão congrega representantes do Governo Federal e de instituições públicas e privadas representativas dos diversos setores do turismo brasileiro, possuindo, atualmente, 73 membros, de maneira que possam, por meio de reuniões e de grupos de trabalho, nas câmaras temáticas, entre outros, contribuírem na formulação e aplicação da Política Nacional de Turismo e dos planos, programas, projetos e atividades dela derivados.

De acordo com Brandão (2010), e corroborando as análises da pesquisa de campo, embora o conselho nacional seja de caráter consultivo, tem grande influência sobre a Política Nacional de Turismo devido à sua capacidade de interferir na inclusão ou exclusão de assuntos da agenda governamental e nos planos nacionais, em níveis distintos e pautados em relações assimétricas.

Por ser um conselho com uma quantidade muito expressiva de membros e as reuniões ocorrerem trimestralmente, seus debates, normalmente, não ficam restritos ao momento da reunião. Entretanto, as câmaras temáticas não funcionam a contento, impossibilitando o uso de um instrumento que poderia trazer resultados substanciais. Há, portanto, um sistema de relações de poderes (Raffestin, 1993) pautado na hegemonia, que dialogam fora desta rede para concretizar as ações articuladas. Assim, o modelo de planejamento exclui a participação da sociedade em geral, o que acaba por definir sua verticalidade e não consolidando, plenamente, um sistema democrático, portanto, uma construção horizontal.

No âmbito Estadual, a instância de governança Estadual - representante legal - tem como responsabilidade, planejar e coordenar ações, em âmbito regional e local; articular, negociar e estabelecer parcerias; monitorar e avaliar as ações do Programa em âmbito local; e produzir e disseminar dados e informações. Desse modo, deve-se possibilitar que os agentes públicos, privados e do terceiro setor participem da elaboração, implementação e monitoramento da Política Nacional de Turismo por meio dos programas e ações do setor.

No RN, o Conselho Estadual de Turismo (Conetur), foco deste trabalho, é um órgão, instituído com o intuito de discutir assuntos relativos à atividade turística em prol do seu desenvolvimento, de acordo com os princípios da gestão descentralizada. Conforme o Cap. I Art. $1^{\circ}$ de seu Regimento Interno, o Conetur é um órgão público colegiado de assessoramento, com caráter consultivo, vinculado, diretamente à Secretaria de Estado do Turismo (Setur).

Ainda há que considerar a existência de outras instâncias de governança em turismo em âmbito regional antes de proceder à análise focada no Conetur. O RN é composto, oficialmente, a partir de 2013, por cinco conselhos regionais compreendendo as regiões turísticas, a saber: o Conselho do Polo Costa das Dunas, o Conselho do Polo Agreste/Trairi, o Conselho do Polo Costa Branca, o Conselho do Polo Seridó e o Conselho do Polo Serrano.

Um conselho regional que merece destaque nesta análise é o Conselho Polo Costa das Dunas, que foi o primeiro conselho regional a ser criado no RN, ainda em 1999 e institucionalizado pelo Decreto ${ }^{\circ}$ 18.186/2005. Diferentemente do Conetur, que foi fortalecido pelo PRT, o Polo Costa das Dunas emerge dos investimentos oriundos do Prodetur (sendo anterior), que teve sob a gerência o Banco do Nordeste durante a primeira e segunda fase do programa cabendo-lhe dois papéis: o de secretaria executiva e de financiador das ações do 
Prodetur que tinha a obrigatoriedade de perpassar pelo crivo do conselho. A coordenação desse conselho é de responsabilidade do governo do estado, e nesse caso, especificamente da Secretaria Estadual de Turismo.

Constata-se que esse é o conselho regional mais assíduo no estado, contabilizando mais de 60 reuniões ordinárias realizadas desde a sua criação. Suas reuniões devem ser sistemáticas (bimestralmente), obedecendo a uma linearidade nos debates que objetivam discutir problemáticas de acordo com os interesses da atividade e não, apenas, de um setor específico; há uma agenda de compromissos que é gerada tanto por parte da gestão quanto pelos membros conselheiros, discutidas nas câmaras temáticas, trazendo, respaldando e fortalecendo as ações desenvolvidas. Desse modo, o conselho nasce com objetivos claros, recursos (humanos) e capital específico para atuar, que, conforme prevê Boisier (2000), Putnam (2004) e Sen (2000), são fatores importantes no processo de desenvolvimento.

Convém sinalizar que a maioria dos representantes que congrega esse conselho regional faz parte do conselho estadual e, por isso, constantemente, há uma confusão a respeito do que vem a ser o conselho regional (Conselho Polo Costa das Dunas) e o conselho estadual (Conetur), evidenciada tanto na leitura das atas quanto na pesquisa de campo, sendo recomendação dos seus integrantes a sua unificação, visto que seus debates se tornam similares:

"Nós somos os mesmos basicamente, entre o Polo Costa das Dunas e o Conetur, então fica uma pauta repetitiva, fica meio exaustivo, até as pessoas mesmo se confundem. Eu me pego pensando a lógica disso, se somos os mesmos e a lógica é a mesma [...] Eu tenho muito mais recordação das ações que foram discutidas no Polo Costa das Dunas. Por exemplo: uma lei que obriga os taxistas a se capacitarem, foi o Polo Costa das Dunas; reordenamento da orla, foi o Polo Costa das Dunas; a estrada que liga Tibau, foi o Polo Costa das Dunas. Então, o polo era a instância responsável pelo Prodetur, e o Prodetur significava dinheiro, então tinha uma efetividade e desdobramento. E o dinheiro atravessa relações e dinheiro facilita as ações” (TS, 2015, grifo nosso).

Para tanto, essa confusão emerge porque o turismo do estado acontece, principalmente, na capital e regiões circunvizinhas, conforme evidenciado nas entrevistas, que é também a área do Conselho Polo Costa das Dunas e foco de interesse de todo o estado. Sem embargo, são instâncias de governanças distintas, já que uma deve discutir problemática e soluções de todo o estado e a outra, apenas, de uma região, mas que não conseguem ser visualizadas por seus membros participantes, justamente pela característica de concentração do fluxo e interesse do turismo na capital do estado.

Ao analisarmos especificamente o Conetur, percebe-se que igualmente a criação dos demais conselhos de turismo no Brasil remonta da década de 1990, especificamente de 1989, fruto de uma mudança institucional do Estado. No entanto, o seu primeiro Regimento Interno foi criado apenas no ano de 2006, e reformulado em 2009, denotando o caráter de permanente reestruturação normativa.

O Conetur atua nos seguintes procedimentos, segundo seu documento normativo: são realizadas reuniões ordinárias bimestralmente e as reuniões extraordinárias quando convocado pelo presidente, obtendo no mínimo $20 \%$ de quórum. O local de realização se dá via rodízio de espaços disponibilizados junto a instituições que compõem o conselho, visando o aumento do comprometimento dos conselheiros e redução dos custos. No entanto, observando o registro das atas disponibilizadas, há uma oscilação no que tange à frequência das reuniões, que pode ser observada no gráfico 02.

\section{Gráfico 2: Frequência das reuniões do Conetur}

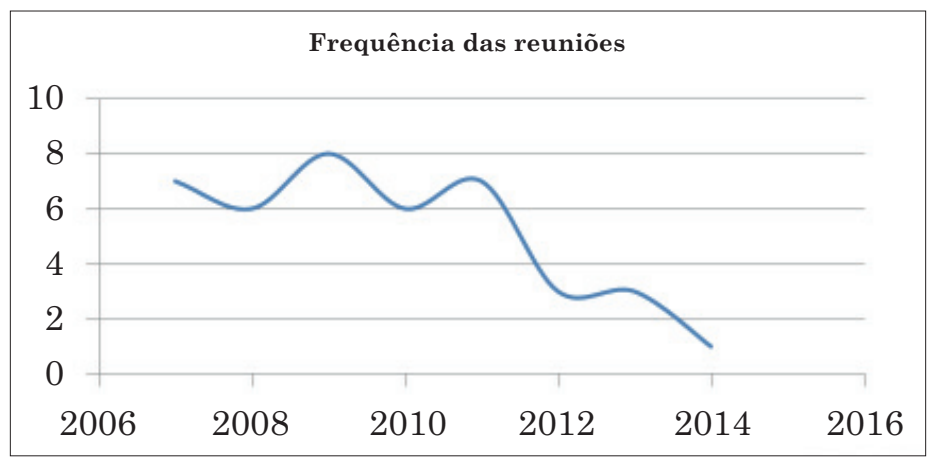

Fonte: Dados da pesquisa. 
A análise do gráfico revela que, há uma maior freqüência nos primeiros anos de estudo da pesquisa, e nos últimos três anos, observa uma queda drástica de freqüência das reuniões, chegando a operacionalizar, apenas duas ao ano. Convém também destacar, conforme evidência das atas, que as reuniões têm ocorrido, majoritariamente, na capital e majoritariamente no centro de convenções, localizada em área nobre e turística da cidade.

A sua estrutura está formada por um plenário, local onde os membros titulares se encontram face a face e fazem suas colocações; uma mesa diretora, formada por um presidente, vice-presidente e secretaria executiva; e as comissões técnicas que tem a função de auxiliar o plenário em relação a temas mais específicos, permitindo que os membros do conselho se tornem mais aptos a discutirem e decidirem sobre determinados assuntos.

As comissões técnicas foram, de fato, criadas no ano de 2007 e reformuladas, ao longo do tempo. Essas comissões devem discutir assuntos de sua competência, levando projetos, planos, sugestões e informações às reuniões. No entanto, desde o ano de 2011, as comissões técnicas foram extintas, devido a três fatores, conforme relato em entrevista com os conselheiros: a) dificuldade de reunir os integrantes para realizar as reuniões; b) não existir nenhum tipo de cobrança neste sentido; e c) uma ausência de direcionamento/gestão das ações de turismo de maneira geral que vai ao encontro da ausência de uma política estadual efetiva.

A gestão está sobre a Secretaria Estadual de Turismo, e embora busque trabalhar de forma descentralizada, a sua gestão não está focada para tal, uma vez que em seu regimento não menciona a participação como prioridade de suas ações, apenas que está voltada ao desenvolvimento da atividade turística de forma geral. Além disso, a indicação nata de uma secretaria para ocupar o cargo, não só fere o princípio representativo, como também indica monopólio, configurando o poder hegemônico frente aos demais segmentos que estão sendo representados dentro do conselho. É importante destacar que existindo mudança de secretário de turismo do Estado, o conselho estará condicionado também a estas alterações, que trará consigo um novo modo de pensar, de discutir, isto é, de gerir, incitando, em muitos casos, ações descontínuas.

A formação do conselho, também é um dado importante que deve ser considerado na sua atuação. De acordo com o Regimento Interno não é paritária e por isso contém discrepâncias entre o número de assentos para o setor público e iniciativa privada, em comparação com o terceiro setor. O Conetur contém 35 conselheiros, obedecendo a seguinte proporcionalidade:

i - Esfera Federal - 03 membros; ii - Esfera Estadual - 05 membros; iii - Conselhos Regionais de Turismo - 05 membros; iv - Esfera Municipal - 02 Municípios Indutores de Turismo; v - Terceiro Setor - 05 membros a serem escolhidos dentre organizações não governamentais - ONG's e associações comunitárias, garantindo, no mínimo 01 vaga para a comunidade científica; que tenham atuação nas áreas de turismo, e que demonstrem interesse nos impactos do turismo; vi - Setor Privado - 15 membros (federações, associações e sindicatos, trade turístico, sistema "S"). (Título II Da Composição e do Funcionamento, Capítulo I da Representatividade e Composição do Conetur, Arts. $5^{\circ}$ e $6^{\circ}$ do Regimento Interno).

Os representantes do governo e iniciativa privada são sobre-representados, definindo, em muitos casos, a capacidade de cada ator nos processos participativos ficando evidente a sobre-representação dos atores públicos e privados nesta arena.

Ademais, é importante sinalizar como são escolhidas as entidades de origem dos conselheiros, constituindo um dado relevante no que tange a representatividade e legitimidade da mesma. O Regimento Interno é claro ao afirmar que estabelece formas diferenciadas para eleger membros de cada segmento. No caso do setor público ocorre por agentes públicos titular de cargo da direção administrativa. No setor privado, pela relação da entidade com o setor turístico e indicação. E o terceiro setor por meio de seleção, que além de comprovar envolvimento com a atividade, deve passar por votação dos demais setores envolvidos. Com isso, a autonomia de representantes de entidades não-governamentais fica comprometida e o processo representativo, torna-se pouco legítimo.

Com base no exposto, observa-se uma série de irregularidades no desenho do conselho tendo, como base, o seu próprio Regimento Interno, que estabelece normas, conforme pode ser visualizado no quadro 3.

Desse modo, embora exista um documento que venha regulamentar as ações deste conselho, elas não são cumpridas, existindo uma desconexão entre o que se pretende ou se propaga e o que, de fato, está ocorrendo no interior do conselho. 


\section{Quadro 3: Correlação entre determinações do Regimento Interno do Conetur e sua operacionalização}

\begin{tabular}{|c|c|c|}
\hline Quesitos & $\begin{array}{l}\text { Determinações do regimento } \\
\text { interno do Conetur do ano de } 2009\end{array}$ & Operacionalização do Conetur \\
\hline $\begin{array}{l}\text { Frequência da } \\
\text { reunião }\end{array}$ & Bimestralmente & $\begin{array}{l}\text { Ocorre de acordo com o perfil da } \\
\text { gestão do momento. }\end{array}$ \\
\hline Local da reunião & Via rodízio de espaços & $\begin{array}{l}\text { Normalmente no mesmo local - } \\
\text { Centro de } \\
\text { Convenções de Natal/RN/Brasil }\end{array}$ \\
\hline $\begin{array}{l}\text { Formação da mesa } \\
\text { diretora }\end{array}$ & $\begin{array}{l}\text { Se o presidente for do setor público } \\
\text { o vice-presidente deve ser do setor } \\
\text { privado, e vice-versa. }\end{array}$ & $\begin{array}{l}\text { Sempre do órgão Estadual de } \\
\text { Turismo }\end{array}$ \\
\hline $\begin{array}{l}\text { Tempo de validade } \\
\text { da direção do } \\
\text { conselho }\end{array}$ & Dois anos não podendo se reeleger & $\begin{array}{l}\text { Dependência do Órgão Estadual de } \\
\text { Turismo, quando este muda, } \\
\text { consequentemente há uma troca de } \\
\text { gestão do conselho. }\end{array}$ \\
\hline Comissões técnicas & $\begin{array}{l}\text { É facultada a existência, mas que } \\
\text { é um excelente instrumento para } \\
\text { a realização de estudos, pesquisas, } \\
\text { programas e projetos relacionados ao } \\
\text { turismo. }\end{array}$ & Foi extinta \\
\hline $\begin{array}{l}\text { Formação do } \\
\text { conselho }\end{array}$ & Equilíbrio & $\begin{array}{l}\text { Existem } 35 \text { membros, sendo } 15 \text { do } \\
\text { setor } \\
\text { privado, } 15 \text { do setor público e apenas } \\
5 \text { para o terceiro setor. }\end{array}$ \\
\hline
\end{tabular}

Fonte: Dados da pesquisa.

De acordo com Avritzer (2007) o ideal de igualdade está na apresentação de temas e o debate por todos os sujeitos, por isso outro fator importante na análise das regras que estruturam a dinâmica de funcionamento está no fato de quem propõe a pauta das reuniões e como se chegam às decisões. No Conetur, a proposta da pauta está a cargo da secretaria executiva, que também recebe sugestões.

O que se pode observar, de acordo com a análise dos dados documentais e empíricos, é que os conselheiros têm poder de voz maior que o de proposição, isto é, embora os conselhos sejam espaços de oportunidade de expressão, ainda é o Estado que detém a centralidade manifestada na maioria dos temas para debate, conforme evidencia a analise documental e de conteúdo:

"Todo debate que gira em torno do assunto é meio que jogado fora. Porque nós dizemos que é de um jeito e no final acontece como o governo quer [...] Hoje governo vai, coloca na pauta, faz uma exposição e não coloca em votação. Então o que eu estou fazendo nesse conselho? Eu só venho escutar o que o governo quer e pronto? Sinceramente está entrando em descrédito" (IP07, grifo nosso).

"O Conetur não é um órgão deliberativo, apenas consultivo. Então nós lançamos as propostas, debatemos as propostas e ai fica a cargo do Estado de fomentá-las. Só que o Estado não tem dinheiro, diz que não tem dinheiro para conseguir manter esse processo. E acaba que todas as nossas discussões são esquecidas ou acabam não sendo tocadas a fundo" (TS01, grifo nosso).

O tipo de decisões contribui para verificar o grau de efetividade do conselho e indicar o grau de influência na formulação da política e no controle público sobre as ações do Estado. Pode-se decidir, assim, sobre um leque variado de temas, como por exemplo, relacionado à política pública, até questões mais específicas que podem tratar da estrutura de funcionamento do conselho.

Observa-se no conselho que as questões mais discutidas estão relacionadas à elaboração de projetos e ao encaminhamento de ações das comissões indicando, de modo geral, um baixo grau de efetividade, uma vez que suas decisões produzem menor impacto sobre a política. As questões que foram mais discutidas em uma parte das reuniões, tais como a organização interna e encaminhamento de documentos, 
Quadro 4: Tipo de decisões que são debatidos em reuniões

\begin{tabular}{|l|c|}
\hline \multicolumn{1}{|c|}{ Tipo de decisão } & Total \\
\hline Projetos & $* * * * * *$ \\
\hline Encaminhamentos das ações das comissões & $* * *$ \\
\hline Encaminhar documentos & $* * *$ \\
\hline Criar comissão & $*$ \\
\hline Infraestrutura & $*$ \\
\hline Qualificação profissional & $*$ \\
\hline Seguranças & $*$ \\
\hline Parcerias & $*$ \\
\hline Prestação de contas & $*$ \\
\hline Outros & $* *$ \\
\hline
\end{tabular}

Fonte: Dados da pesquisa.

denotam o caráter permanentemente reestruturativo do conselho. Por último, as questões que foram menos discutidas denotam que muito das ações pensadas pelo coletivo, quase nunca chega a se efetivar, conforme evidencia a análise da pesquisa de campo:

"Eu vejo que a gente fica muito na mão de Brasília. A equipe do Prodetur é um pessoal muito interessado, muito empenhado, mas se o pessoal de Brasília não colocar para frente, não sai. Depende tudo de Brasília e pouquíssima coisa passa por aqui” (EE04).

"Ai eu te pergunto: a gente tem o Conetur por que é uma exigência federal? Qual é a pertinência? Não tem dinheiro, não tem equipe. Ai é complicado, menino grandinho, cumprindo obrigação. Temos que saber a razão das coisas estarem sendo feitas" (TS04, grifo nosso).

Neste contexto, constata-se a presença de muitos discursos desarticulados com a prática e/ou ação para o desenvolvimento do turismo. Uma possível explicação para identificar este baixo grau de efetividade ocorre devido a dois fatores: o fato de o conselho se encontrar no estágio ainda de consolidação e o papel obscuro do governo não construindo mecanismos fortes de indução para solucionar os problemas apresentados, atuando apenas nos setores quando lhe é conveniente. Corre-se o risco, assim, de que o Conetur seja um espaço apenas para legitimação de decisões, de modo a cumprir normas que viabilizam o acesso do governo a recursos de todo tipo.

\section{Conselho estadual de Turismo e o processo de desenvolvimento turístico no RN}

É evidente o poder que o Estado tem na delimitação e encaminhamentos das ações de turismo no $\mathrm{RN}$, que também está diretamente associado ao processo de formação do Estado brasileiro, em que sempre buscou formas de responder às distintas pressões mantendo as relações clientelísticas, patrimonialista e centralizada. Confronta-se, com o que propõe autores como Velasco Gonzalez (2013; 2016), Tretin (2016), Dias \& Matos (2012), os quais defendem uma postura mais coordenadora nas suas ações, principalmente neste novo cenário de planejamento e gestão pública em que o Estado vivencia. A postura estatal está arraigada no seu primeiro marco com estruturas verticais e forte dependência dos interesses organizacionais (Emmedoerfe et al, 2011; Cruz, 2000; Emmedoerfer et al, 2016).

Corroborando as ideias de Raffestin (1993), estruturas antigas são reproduzidas, laços, valores e práticas são a repetidas, embora sejam moldadas pela forma com que o território é habitado, não permitindo que o novo ocorra verdadeiramente. Com isso, esse formato influencia na constituição, desempenho e resultado das instâncias de governança que são criadas em todo o território brasileiro, como forma também de operacionalizar o processo de "descentralização" que Brasil vem promulgando nos últimos anos. 
Esse é um jogo político que produz poder no território (Raffestin, 1993). Assim sendo, as decisões tomadas pelos representantes devem ser mutuamente acordadas, mas nem sempre isto ocorre, uma vez que alguns representantes têm voz mais ativa pelo poder de sua representação no conselho e nas instituições/entidades públicas e privadas. Esse poder se deve não só ao fato de existir mais participação e engajamento que esta representação tem dentro do conselho, por meio da frequência e exposição de ideia nas reuniões, mas também pelo fato de serem, na maioria dos casos, representantes do setor produtivo turístico, muitas vezes em "simbiose" com o próprio Estado, com interesse econômico envolvido que determina as regras no uso do território. Isso significa que existe um poder da representação subjacente às decisões tomadas pelo grupo.

É importante considerar também, o modelo de participação restrito, conforme teoria de Alió (2005), por meio de consultas pontuais, geralmente restritas a grupos sociais econômicos, ficando, assim, subordinado às formas e decisões da liderança administrativa.

\section{Considerações finais}

É perceptível que as relações que se estabelecem no interior do processo de desenvolvimento da atividade turística no $\mathrm{RN}$ interferem no Conetur (e vice-versa) através da sua estrutura de funcionamento, da dinâmica de funcionamento, bem como das ações que são engendradas dentro do conselho que repercute o discurso hegemônico da atividade turística, objetivando concentrar o turismo na capital, supervalorizando o segmento turístico de sol e praia e continuar focando no interesse de investimentos externos. Percebe-se ainda que as normas e procedimentos de participação social continuam excluindo a sociedade do processo de planejamento e gestão das localidades.

$\mathrm{O}$ que acontece no RN é reflexo da política nacional que por sua vez influencia diretamente nas decisões e desdobramentos das ações estaduais e regionais. O RN está em sintonia com o Brasil, que tornou as economias mais assimétricas, e busca este trabalho em rede.

Desse modo, para que a participação seja democrática, ela precisa ser livre e deve canalizar-se mediante procedimentos preestabelecidos e conhecidos daqueles que participam, requerendo estruturas de suporte e decisão. Em face da democracia representativa contemporânea, torna-se necessário contar com pessoas competentes que criem condições favoráveis para a articulação entre os atores envolvidos, promovendo princípios de mudança nas localidades, através da implementação das atividades planejadas.

Apesar de toda a dificuldade de operacionalização, os conselhos de turismo se tornam, dessa maneira, um importante instrumento de articulação e discussão das ações em cada esfera. Por esse motivo, há a necessidade de interação entre os diferentes atores, imbuídos de responsabilidade, participação e confiança em todos os elos da cadeia de relacionamento, dialogando, discutindo e definindo as diretrizes para o desenvolvimento da atividade em consonância com a Política Nacional de Turismo.

\section{Bibliografia}

Alió, M. A.

2005. Uma altra Visio sobre lês relacions entre La societat i La natura. Aportacions des d'una recerca participativa sobre El planejament ambiental. Treballs de La Societat Catalana de Geografia. 60: 129-143.

Arretche, M. T. S.

1998. "Tendências no Estudo sobre Avaliação". En: Rico, Elizabeth M. (Eds.). Avaliação de Políticas

Sociais: Uma questão em debate. São Paulo, Cortez: 38-57.

Avritze, L.

2007. "Participação e distribuição nas políticas públicas do Nordeste". Projeto democracia participativa.

Belo Horizonte.

Azevedo, F.F. et al.

2013. "Turismo em Foco: globalização e políticas públicas". En: Azevedo, F. F. et al (Eds.). Turismo em foco. NAEA, Belém.

Azevedo, S.\& Anastasia, F.

2002. "Governança, "Accountability" e Responsividade: reflexões sobre a institucionalização da participação popular em experiências desenvolvidas em Minas Gerais”. Revista de Economia Política, 22(1): 85. 
Baum, T

1994. The development and implementation of national tourism policies. Tourism Management, 15 (3): 185-192.

Boisier, Sergio.

2000. "Desarrollo (Local): de qué estamos hablando?" En: Becker, Dinizar Fermiano; Bandeira, Pedro Silveira (Eds.). Desenvolvimento Local e Regional: Determinantes e desafios contemporáneos. Santa Cruz do Sul, EDUNISC.

Brandão, Pâmela de M.

2010. Análise da rede política do turismo brasileiro. Dissertação (mestrado em Turismo). Programa de Pós Graduação em Turismo. Universidade Federal do Rio Grande do Norte. Natal.

Banco do nordeste.

2013. Prodetur NE II - Situação atual: etapas de planejamento. Disponível em: HTTP://www.bnb.com.br/ contect/aplicacao/PRODETUR/Prodetur_ne2/gerados/situacao_atual. [consulta: 10 de Dezembro 2016]. Cacho, A. do N. B. \& Azevedo, F. F. de.

2010. "O turismo no contexto da sociedade informacional". Revista Brasileira de Pesquisa em Turismo. 4(2): 31-48.

Cruz, Rita de Cássia.

2000. Políticas do turismo e território. São Paulo. Contexto.

Dias, R. \& Matos, F.

2012. Política pública: princípios, propósitos e processos. São Paulo: Atlas.

Emmendoerfer, M. et al.

2016. Destinos indutores e desenvolvimento turístico regional: um problema de intergovernabilidade? Pasos: Revista de Turismo y Patrimonio Cultural 14(3): 737 - 750.

Emmendoerfer, M. et al.

2011. "Evidências de Inovação Social na Gestão Pública do Turismo em Minas Gerais - Brasil: O Modelo de Circuitos Turísticos em Análise". PASOS. Revista de Turismo y Patrimonio Cultural. 9(2): 397-410.

Fonseca, Maria A. P. da.

2006. Espaço, Políticas de turismo e competitividade. Natal: EDUFRN.

Fonseca, M.A. P. da, \& Taveira, M. da S.

2009. "O modelo turístico potiguar e seus efeitos sócio espaciais nas comunidades litorâneas". VI Seminário da Associação Brasileira de Pesquisa e Pós-Graduação em Turismo. Universidade Anhembi Morumbi - UAM/ São Paulo/SP.

Gil, Antonio C.

1994. Métodos e técnicas de pesquisa social. São Paulo: Atlas.

Guimarães, Maria C. L.

2002. "O debate sobre a descentralização de políticas públicas: um balanço bibliográfico". Organizacoes \& Sociedade. 9(23).

Godoy, Arilda S.

1995. "Pesquisa qualitativa: tipos fundamentais". Revista de Administração de Empresas. São Paulo, 35 (3).

Governo do Estado do Rio Grande Do Norte.

2009. Gabinete Civil. Coordenadoria de Controle dos Atos Governamentais. Regimento Interno do Conetur. Decreto ${ }^{\circ} 21.382$, de 10 de Novembro de 2009.

Governo do Estado do Rio Grande Do Norte.

2006. Gabinete Civil. Coordenadoria de Controle dos Atos Governamentais. Regimento Interno do Conetur. Decreto 18.893, de 14 de Fevereiro de 2006.

Maranhão, C. H. da S.

2012. Turismo, capital social e produção do espaço: uma leitura a partir do município de Natal/RN no período de 1980 a 2012. Dissertação (Mestrado em Turismo) - Centro de Ciências Sociais Aplicadas. Universidade Federal do Rio Grande do Norte. 166f. Natal, RN.

Maranhão, C. H. da S.\& Azevedo, F.F.

201). "Os processos de planejamento e gestão do turismo em Natal (RN) e o fomento do turismo de base local: uma articulação necessária”. Revista Brasileira de Ecoturismo, São Paulo, 7(1): 103-118. OCDE,

2013. Governança multnível para políticas de desenvolvimento regional mais eficazes. In Relatório territorial da OCE: Brasil, 2013. OCDE Publishing. 161-231. doi: 10.1787/9789264189058-pt

Putnam, R.

2006. Comunidade e democracia: a experiência da Itália moderna. Rio de Janeiro: FGV. 
Raffestin, Claude.

1993. Por uma geografia do poder. São Paulo: Ática.

Richardson, Roberto J.

2008. Pesquisa social: métodos e técnicas. 3. ed. São Paulo. Atlas.

Santos, Milton.

2002. A natureza do espaço: Técnica e Tempo, Razão e Emoção. São Paulo. USP.

Santos, Milton.

2010. Por uma outra globalização: do pensamento único à consciência universal. $19^{a}$ ed. Rio de Janeiro,

Record.

Sen, Amartya.

2000. Desenvolvimento como liberdade. $1^{\mathrm{a}} \mathrm{ed}$. São Paulo: Companhia das Letras.

Souza, M. J. L. de; Rodrigues, G. B.

2004. Planejamento Urbano e Ativismos sociais. São Paulo: UNESP.

Tretin, F.

2016. Governança turística em destinos brasileiros: comparação entre Armação dos Búzios/RJ, Paraty/

RJ e Bonito/MS. Pasos: Revista de Turismo y Patrimonio Cultural, 14 (3): 645-658.

Velasco Gonzalez, M.

2013. Gestión pública Del turismo. La gobernanza. In Fernández, J. \& Sánchez, Y. (Eds.). Gestión estratégica sostenible de destinos turísticos. Sevilla: Universidad Internacional de Andalucía.

Velasco, M.

2016. Entre El poder y la racionalidad: gobierno Del turismo, política turística, planificación turística y gestión pública Del turismo. Pasos: Revista de Turismo y Patrimonio Cultural. 14 (3): 577-594.

Wan, Y. \& Bramwell, B.

2015. Political economy and the emergence of a hybrid mode of governance of tourism plannng. Tourism Management. 50: 316-327. 